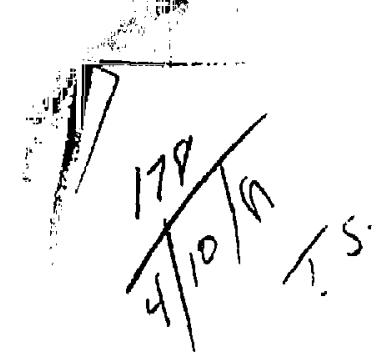

$\int_{1} a^{104}$

Or. 2509

I CRL. 85666

PREPRINT

FPPAC--A Two-Oimensional Multispecies

Nonl inear Fokker-Planck Package

M.G. Mccoy, A.A. Mirin, and J, Killeen

This paper was prepared for submittal to Journal of Computer Physics Communications

Marsh $198^{\circ}$

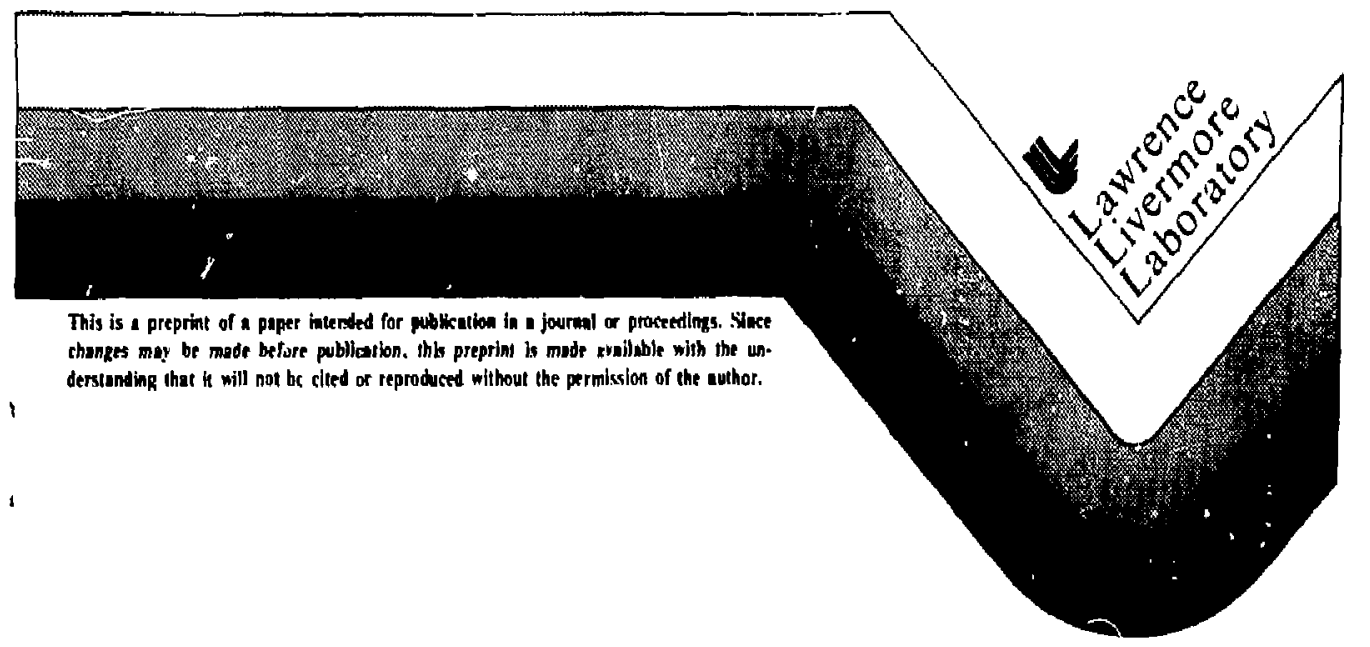




\section{PROGRAM SUMMARY}

Title of program: FPPAC

Catalogue number:

Program obtainable from: CPC Program Library, Queen's University of Belfast, N. Ireland

Computer for which the program is designed and others on which it is operable:

Computer: CRAY-1 Installation: National Magnetic Fusion Energy CDC- 7600 Computer Center, lawrence Livermore National Laboratory

Operating system or monito: under whlch the program is executed:

CTSS on CRAY, LTSS on 7600

Programing language used:

FORTRAN (ANSI 77)

High speed storage required: $304000 \mathrm{~B}$ words (for mesh s1ze 71 (v) by 31 ( $\theta$ ), 2 general spectes, 1 Maxwellian spectes, 9 Legendre polynomials).

No. of bits in a ward: 64 (CRAY), 60 (7600)

Overlay structure: None

No. of magnetic tapes required: None

Other peripherals used: None

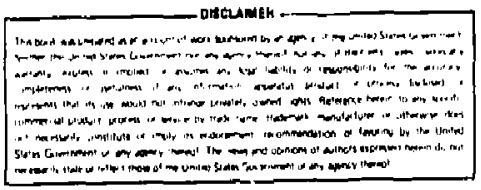

Work performed under the ausplices of the U.S.D.0.E. by Laurence Livermore National Laboratory under contract W-7405-ENG-48. 
No. of cards in combined program and test deck: 7000 per macinine

Card punching code: 026

CPC Library subprograms used: None

Reference to other published version of this program: None

Keywords: Two-Dimensional, Multispecles, Implicit, Nonlinear, Fokker-Planck

SIMARY

\section{Nature of the Physical Problem}

The complete nonlinear multispecles Fokker-Planck collision operator for a plasma in two-dimensional velocity space is solved. The operator 18 expressed In terms of spherical coordinates (vuspeed, omangle between velocity and magnetic field directions, paztinuthal angle) under the assumption of azimuthal symnetry. Provision is made for additional physics contributions.

\section{Method of Solution}

The Fokker-Planck equation 1s solved using finite ilfferences, Spatia: derivatives are approximated by central differences. TIme-advancement is accomplished through elther implicit operator splitting, an alternating directisn iaplicit (ADI) algorithm, or fully implicit differencing. (In the latter case the user must supply his own nine-banjed linear systems solvor.) The Fokker-planck coefficients and their derivatives are computed by expunding the distribution functions and the Rosenbluth potentials ${ }^{(1)}$ in legendre series, and equating the respective series coefficients. 
Restrictions on the Complexity of the Yroblen

The user must adfust the number of meshpoints in the two coordinate directions as well as the number of Legendre polynonlals uged to calculate the Fokker-Planck coefficlents, Sufficlent accuracy for most problems is attalned on both the CRAY and 76J0. However, double precision should be used on a 32-bit-wc rd machine.

\section{Typical Rurining T1me}

(CRAY) 9.6 $u s /$ meshpoint/species are required to compute the Fokker-Planck coefficients. $1,9 \mathrm{is} /$ meshpoint are requited to time-advance the distribution function for one specles lising implicit operator splitting. These times vary to some extent with the gesh configuration due to variations in vectorization efficlency. The package runs 10-12 times slower on the CDC-7600.

Unusual reatures of the Program

None

\section{References}

1. J. Killeen, A.A. Mtrin, and M.E. Rensink, "The Solution of the Kinetlc Equacions for a Multispecies Plasma," in Methods in Computat lonal Phys tcs 16. Academic Press (1976), 389.

2. J. Killeen and A.A. MIrin, "Numerical colution of the Fokker-Planck Equat lons for a Multispecles Plasma," In College In Theoretical and Computatlonal Plasma Physics, Trteste (1977), LAEA, VLenna, 27.

3. M.G. MeCoy, A.A. Mirin, and J. Killeen, "A Vectorized Fukker-Planck Package for the Cray-1," Sclentific Computer Exchange Meeting, Livermore (1979), UCRL -83206 .

4. A.I. Shestakov, "Users Manual for LLUCG," Lawrence Livermore Laborazory Internal Document UCID-18560 (1980).

Note: Separate source decks for CRAY-I and COC-7600 versions are provided. 
LONG WRITE-UP

1. INTRODICIIIN

Ir. the simulation of magnetically confined plaswas in which the lons or electrons are non-Maxwellian and where a knowledge of the distribution functions is important, kinetic equations nust be solved. In both wirror and tokamak confinement devices non-Maxwellian plaswas may be present. This may be due to the presence of extensive loss reglons in velocity space or to the injection of energetic neutral beams. The kinetic equation to be solved is the Boltzmann equation with Fokker-Flanck Coulomb colliston terms.

This nonlinear partial differential equation, which describes the evolution of the distribution functions of all charged specles in the plaswa. has seven independent varlables (three spatlal coordinates, three veloctly coordinates and time). Consequently, a number of stmplfications must be Introduced Into the equation to allow any present day computer to solve the problem. One can reduce the number of independent varlables to three by neglecting spatial dependence and by assuming azlouthal symetry of the distribution functions about the direction of the magnetic. fleld. With these simplifications, Roscntiuth, MacDonald and Judd (5) succeoded in expressing the equation in a form sultable for solution on a computer.

Subsequently, a number of computer programs have been developed (1),(6) whicl solve this equation. These Fokker-Planck codes are frequently Incorporated in larger codes which sinulace additional physical processes such as quas L-linear diffusion due to radlo frequency heating ${ }^{(7)}$ and spatial diffusion of the plasma ${ }^{(8)}$.

A problem encountered in these programs has been the long run times requited to solve the Fokker-Plancik equation, and this problem is aggravated in studies for which it is necessary to solve for the operator at a large number of spatial polats or when very high resoletion is required. A further problem occurs when making Improvements to the numerical algortthm, for changes haye to be made in the source decks of all of the coses employing the same form of the Fokker-Planck operator. These two difficulties are alleviated by a newly 
developed program consisting of a skeleton driver plus package, FPPAC, th: latter of which time-advances the Fokkcr-Planck equations in 20 velocity space for an arbitrary number of charged "general" specles in the presence of an arbitrary number of fixed barkground Maxwellian specles.

The driver/package nay be run as a stand-alone code, thereby serving as the kernel of a new code, or the package itself nay be stripped from the drtver and incorporated into an existing code $(7),(8),(9)$. Moreover, addttlonal physles (e.g., rf heating ${ }^{(7)}$, magnettc compression $(1)$, neutral injection(1), may be represented by merely setsing existing array elements; detalled instructions are provided in the source 11sting. There are two versions of the package--one optimlzed for the CRAY-1 and the other optiolzed for the COC-7600. The CRAY version runs an order of wagnltude faster than the 7600 version.

2. THE FORKER-PLANCK OPERATOR

The Boltzmann equation for the dtstribution function of each plasma specles is given by

$$
\frac{\partial f_{a}}{\partial t}+\underline{v} \cdot \frac{\partial f_{a}}{\partial \underline{x}}+\frac{F}{m_{g}} \cdot \frac{\partial f_{a}}{\partial \underline{v}}=\left(\frac{\partial f_{a}}{\partial t}\right)_{c}
$$

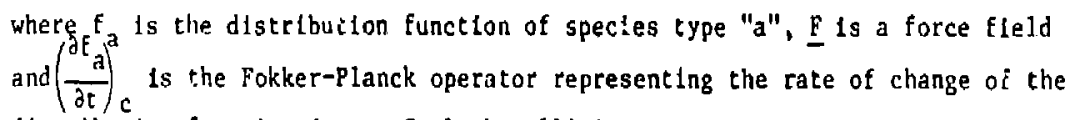
distribution function due to Coulomb collisions.

With the simplifying assumpt ton that the Fokker-planck operator depends only on the velocity, $\underline{v}$, and not upon spatial position, $\underline{x}$, the operator as derlved by Rosenbluth et al. ${ }^{(5)}$ has the form 


$$
\left(\frac{\partial f_{a}}{\partial t}\right)_{c}=\Gamma_{a}\left\{-\frac{\partial}{\partial v_{1}}\left(f_{a} \frac{\partial h_{a}}{\partial v_{1}}\right)+\frac{1}{2} \frac{\partial^{2}}{\partial v_{1} \partial v_{j}}\left(f_{a} \frac{\partial^{2} B_{a}}{\partial v_{1} \partial v_{j}}\right)\right\},
$$

where the usual summing conventions over repeated Indices " 1 " and " $f$ " are to be used and where $\Gamma_{a}=4 \pi z_{a}^{4} e^{4} / m_{a}^{2}$. The "Rrsenbluth potentials" are written as

$$
\begin{gathered}
B_{a}=\left[\left(\frac{z_{b}}{z_{a}}\right)^{2} \ln \Lambda_{a b} \int f_{b}\left(\underline{u}^{\prime}\right)\left|\underline{v}-\underline{v}^{\prime}\right| d \underline{w}^{\prime}\right. \\
h_{a}=\sum_{b} \frac{m_{a}+m_{b}}{m_{b}}\left(\frac{z_{b}}{z_{a}}\right)^{2} \text { \&n } A_{a b} \\
\cdot \int f_{b}\left(\underline{v}^{\prime}\right)\left|\underline{v}-\underline{v}^{\prime}\right|^{-1} d \underline{v}^{\prime} .
\end{gathered}
$$

The Coulomb. logarithm, which depends on boch interacting species, is

$$
\begin{aligned}
\ln \Lambda_{a b} & =\ln \left(\left(\frac{m_{a} \pi_{b}}{m_{a}+a_{b}}\right) \frac{2 a c \lambda_{D}}{e^{2}}\right. \\
& \left.=\sup \left(\frac{2 E_{k}}{m_{k}}\right)_{a, b}^{\frac{1}{2}}\right)-\frac{1}{2},
\end{aligned}
$$

where $a=0.0073$ is the fine structure constant, $\lambda_{D}=\sqrt{E_{e} / 6 \pi n_{e} e^{2}}$ is the Debye length, $E_{k}$ is the energy of species $k, n_{e}$ is the electron density, and $E_{e} 1 s$ the electron mean energy. (The electrons may be treated elther as a general spectes with distrtbution function $f_{e}$ or as a background Maxwellian.) 
Under the further ass'suption that the distribution functions $f_{a}$ ere azimuthally symetric about the direction of the agnatic fleld, the formulation given above may be recast as a two dimengional problem when writtun In spherical polar coordinates $(v, \theta, \phi)$, where $v$ is the speed, $\theta$ is the angle between the velocity vector and the magnatic field, and $\$$ is the atiouthal angle. In this case the density and energy-density of opectes "a" are defined according to

$$
\begin{aligned}
& n_{a}=2 \pi \iint f_{a}(v, \theta) v^{2} \sin \theta d v d \theta \\
& n_{a} F_{a}=m_{a} \int f_{a}(v, \theta) v^{4} \sin \theta d v d \theta .
\end{aligned}
$$

Equation (2) then becomes

$$
\frac{1}{\Gamma_{a}}\left(\frac{\partial f_{a}}{\partial t}\right)_{c}=\frac{1}{v^{2}} \frac{\partial G_{a}}{\partial v}+\frac{1}{v^{2} \sin \theta} \frac{\partial H_{a}}{\partial \theta}
$$

where

$$
\begin{aligned}
& G_{a}=A_{a} f_{a}+B_{a} \frac{\partial f_{a}}{\partial v}+C_{a} \frac{\partial f_{a}}{\partial \theta} \\
& H_{a}=D_{a} f_{a}+E_{a} \frac{\partial f_{a}}{\partial v}+F_{a} \frac{\partial f_{a}}{\partial p} .
\end{aligned}
$$


The coefficients $A_{a}, B_{a}, C_{d}, D_{a}, E_{a}$ and $F_{a}$ are given by:

$$
\begin{aligned}
& A_{a}=\frac{v^{2}}{2} \frac{\partial^{3} g_{a}}{\partial v^{3}}+v \frac{\partial^{2} g_{a}}{\partial v^{2}}-\frac{\partial g_{a}}{\partial v}-v^{2} \frac{\partial h_{a}}{\partial v} \\
& -\frac{1}{v} \frac{\partial^{2} g_{a}}{\partial \theta^{2}}+\frac{1}{2} \frac{\partial^{3} h_{a}}{\partial v \partial \theta^{2}}-\frac{\cot \theta}{v} \frac{\partial g_{a}}{\partial \theta}+\frac{\cot \theta_{1}}{2} \frac{\partial^{2} g_{a}}{\partial v \partial \theta} \\
& B_{B}=\frac{v^{2}}{2} \frac{\partial^{2} g_{B}}{\partial v^{2}} \\
& c_{a}=-\frac{1}{2 v} \frac{\partial g_{a}}{\partial \theta}+\frac{1}{2} \frac{\partial^{2} g_{a}}{\partial v \partial \theta} \\
& D_{a}=\frac{\sin \theta}{2 v^{2}} \frac{\partial^{3} B_{a}}{\partial \theta^{3}}+\frac{\sin \theta}{2} \frac{\partial^{3} B_{a}}{\partial v^{2} 3 \theta}+\frac{\sin \theta}{v} \frac{\partial^{2} B_{a}}{\partial v \partial \theta} \\
& =\frac{1}{2 v^{2} \sin \theta} \frac{\partial \mathrm{B}_{a}}{\partial \theta}+\frac{\cos \theta}{2 v^{2}} \frac{\partial^{2} g_{a}}{\partial \theta^{2}}-\sin \theta \frac{\partial h_{a}}{\partial \theta} \\
& E_{a}=\sin \theta\left[-\frac{1}{2 v} \frac{\partial g_{a}}{\partial \theta}+\frac{1}{2} \frac{\partial^{2} B_{a}}{\partial v^{\partial} \theta}\right]
\end{aligned}
$$




$$
F_{a}=\frac{\sin \theta}{2 v^{2}} \frac{\partial^{2} g_{a}}{\partial \theta^{2}}+\frac{\sin \theta}{2 v} \frac{\partial g_{a}}{\partial v}
$$

As suggested by Rosenbluth et al. (5), the "Rosenbluth potentlals" and the distribution functions themselves may be repregented by expanolong in legendre polynomlals. For this purpose we let

$$
E_{b}(v, \theta, t)=\sum_{l=0}^{\infty} v_{l}^{b}(v, t) \quad P_{l}(\cos \theta)
$$

where

$$
v_{\ell}^{b}(v, t)=\frac{2 l+1}{2} \int_{-1}^{+1} f_{b}(v, \cos \theta, t) \quad P_{l}(\cos \theta) d(\cos \theta) .
$$

The expansions for the potentfals are

$$
g_{a}(v, \theta, t)=\sum_{l=0}^{\infty} \sum_{b}\left(\frac{Z_{b}}{z_{a}}\right)^{2} \text { in } A_{a b} B_{\ell}^{b}(v, t) \quad P_{\ell}(\cos \theta)
$$

and

$$
h_{a}(v, \theta, t)=\sum_{l=0}^{\infty} \quad l\left(\frac{m_{a}+m_{b}}{m_{b}}\right)\left(\frac{L_{b}}{z_{2}}\right)^{2} \quad \ln \Lambda_{a b} A_{l}^{b}(v, t) P_{l}(\cos \theta)
$$




\section{with coefficients}

$$
\begin{aligned}
& A_{l}^{b}=\frac{4 \pi}{2 l+1}\left[\int_{0}^{v} \frac{\left(v^{\prime}\right)^{l+2}}{v^{l+1}} v_{l}^{b}\left(v^{\prime}, t\right) d v^{\prime}\right. \\
& \left.+\int_{v}^{\infty} \frac{v^{\ell}}{\left(v^{\prime}\right)^{l-1}} v_{l}^{b}\left(v^{\prime}, t\right) d v^{\prime}\right) \\
& B_{l}^{b}=-\frac{4 \pi}{4 l^{2}-1} \mid \int_{0}^{v} \frac{\left(v^{\prime}\right)^{l+2}}{v^{l-1}} \\
& \text { - }\left(1-\frac{\ell-1 / 2}{l+3 / 2} \frac{\left(v^{\prime}\right)^{2}}{v^{2}}\right) v_{l}^{b}\left(v^{\prime}, t\right) d v^{\prime} \\
& +\int_{v}^{\infty} \frac{v^{\ell}}{\left(v^{\prime}\right)^{\ell-3}}\left(1-\frac{\ell-1 / 2}{\ell+3 / 2} \frac{v^{2}}{\left(v^{\prime}\right)^{2}}\right) \\
& \text { - } v_{\ell}^{b}\left(v^{\prime}, t\right) d v^{\prime} \mid \text {. }
\end{aligned}
$$

It is natationally convenient to define four functionels

$$
\begin{aligned}
& M_{\ell}(w)(v)=\int_{V}^{\infty} w(y) y^{(l-l) d y} \\
& N_{\ell}(w)(v)=\int_{0}^{V} w(y) y^{(2+i l)} d y \\
& R_{\ell}(w)(v)=\int_{V}^{\infty} w(y) y^{(3-l)} d y
\end{aligned}
$$




$$
E_{\ell}(w)(v)=\int_{0}^{v} w(y) y^{(4+l)} d y .
$$

Using these functionals, Eqs. (18) and (19) become

$$
\begin{aligned}
A_{l}^{b} & =\frac{4 \pi}{(2 l+1)}\left[v^{-l-1} N_{l}\left(v_{l}^{b}\right)+v^{l} M_{l}\left(v_{l}^{b}\right)\right] . \\
B_{l}^{b} & =\frac{4 \pi}{2 l+1}\left\{\frac{1}{(2 l+3)}\left\{v^{-l-1} E_{l}\left(v_{l}^{b}\right)+v^{l+2} M_{l}\left(v_{l}^{b}\right)\right]\right. \\
& \left.-\frac{1}{(2 l-1)}\left\{v^{1-\ell} N_{l}\left(v_{l}^{b}\right)+v^{l} R_{l}\left(v_{l}^{b}\right)\right]\right\} .
\end{aligned}
$$

Evalua:-1on of the coefflclents defined in Eqs. (8)-(13) requites derivatives of the "Rosenbluth potentials". These may be obtained through term by term differentiation of Eqs. (16)-(17). To obtain derivatives with rospect to $v$ requires differentiation of the right side of Eqs. (24)-(25). Th!s is done analytically.

The resulting expressions are

$$
\begin{aligned}
\frac{\partial A_{l}^{b}}{\partial v} & =\frac{4 \pi}{(2 l+1)}\left\{l v^{\ell-1} M_{l}\left(v_{l}^{b}\right)-(l+1) v^{-l-2} N_{l}\left(v_{l}^{b}\right)\right] \\
\frac{\partial B_{l}^{b}}{\partial v} & =\frac{4 \pi}{(2 l+1)}\left\{\frac{1}{(2 l+3)}\left[(l+2) v^{l+1} M_{\ell}\left(v_{l}^{b}\right)-(l+1) v^{-l-2} E_{l}\left(v_{l}^{b}\right)\right]\right. \\
& \left.-\frac{1}{(2 l-1)}\left[\ell v^{l-1} R_{l}\left(v_{l}^{b}\right)-(l-1) v^{-l} N_{l}\left(v_{l}^{b}\right)\right]\right\}
\end{aligned}
$$




$$
\begin{aligned}
& -12- \\
& \frac{\partial^{2} B_{l}^{b}}{\partial v^{2}}=\frac{4 \pi}{(2 \ell+1)}\left\{\frac{(l+1)(l+2)}{(2 l+3)}\left[v^{-\ell-3} E_{l}\left(v_{l}^{b}\right)+v^{l} M_{l}\left(v_{l}^{b}\right)\right]\right. \\
& \left.-\frac{\ell(l-1)}{(2 l-1)}\left[v^{-l-1} N_{\ell}\left(v_{l}^{b_{l}}\right)+v^{\ell-2} R_{l}\left(v_{l}^{b}\right)\right]\right\} \\
& \frac{\partial^{3} \mathrm{~B}_{\ell}^{\mathrm{b}}}{\partial v^{3}}=\frac{4 \pi}{(2 \ell+1)}\left\{\frac { 1 } { ( 2 \ell + 3 ) } \left[\ell(\ell+1)(\ell+2) v^{\ell-1} M_{\ell}\left(v_{\ell}^{b}\right)\right.\right. \\
& \left.-(\ell+1)(\ell+2)(\ell+3) v^{-\ell-4} E_{\ell}\left(v_{\ell}^{b}\right)\right] \\
& -\frac{1}{(2 l-1)}\left[\ell(\ell-1)(\ell-2) v^{-\ell-3} R_{\ell}\left(v_{\ell}^{b}\right)\right. \\
& \left.\left.-(\ell+1)(\ell)(\ell-1) v^{-\ell-2} N_{\ell}\left(v_{l}^{b}\right)\right]\right\}
\end{aligned}
$$

Derivatives with respect to $\theta$ are also done analytically.

\section{BOUNDARY CONDITIONS}

Eq. (5) may be solved clther in full velocity space or In some subspace. The full velocity-space boundary conditions are

$$
f_{a}(v=0,0) \text { is independent of } \theta
$$

$$
\frac{\partial f_{a}}{\partial v}(v=0, \theta=\pi / 2)=0
$$

$f(v=\infty, \theta)=0$ 


$$
\frac{\partial f_{a}}{\partial \theta}(v, \theta=0)=\frac{\partial f_{a}}{\partial \theta}(v, \theta=\pi)=0
$$

For prohlems with symetry about the angle $\theta=\pi / 2$, it is assumed that

$$
\frac{\partial f_{3}}{\partial \theta}(v, \theta=\pi / 2) \cdot 0
$$

In situations where there is a loss cone or separacrix in velocity space, a Dirichlet-like condition may be substituted, 1.e., tnstead of using Eqs. $(30)-(33)$, one may spectfy values of $f_{a}$ along curves $\left(v, \theta_{\min }^{a}(v)\right),\left(v, \theta_{\max }^{a}(v)\right),\left(v_{\min }^{a}(\theta), \theta\right),\left(v_{\max }^{a}(\theta), \theta\right)$. It is of ten approptlate to combine such Dirlchlet conditions with fult velocity space conditions, as in the case of electrons trapped in a magnetic well in the presence of a confining potental. $\langle 9\rangle$

\section{MESH DEFINITION}

The independent vartables $v$ and $\theta$ are represented by meshes $\left\{v_{j}\right\}_{j=l}$ and $\left\{0_{1}\right\}_{i=1}^{I}$, respectively. These meshes do not have to be uniform. The first velocity meshpoint, $v_{1}$, will always equal 0 . The thet domaln may be of two types:

(1) assumed symmetry of the distribution functions about $\theta=\pi / 2$, in which case $\theta_{I}=\pi / 2$. This scenarto utilizes an extra reflection point $\theta_{1+1}=\pi$ ${ }^{\theta} \mathrm{I}-1$

(2) no assumed symmetry of the distribution functions. Here, the theta mesh is Laken to be syometric about $\theta=\pi / 2$, with a meshpoint right at $\theta=\pi / 2$, so that I must be odd. In either case, $\theta$, need sot be equal to 0 . 
5. MMERICAL INTEGRATION IN VELOCITY SPACE

Numerical integration in velocity space is accorritished through a variation of trapezoldal integration. In the $v$ direction,

$$
\int f(v) v^{2} d v \approx \sum_{j=1}^{j} a_{j} f\left(v_{j}\right)
$$

where

$$
\begin{aligned}
& a_{1}=v_{2}^{3} / 24 \\
& a_{j}=v_{j}^{2}\left(\frac{v_{j+1}-v_{j-1}}{2}\right), \quad 1<j<J \\
& u_{J}=v_{J}^{2}\left(\frac{v_{J}-v_{J-1}}{2}\right) .
\end{aligned}
$$

Eq. (36) assumes $f(v)$ is constant between $v=0$ and $v=v_{2} / 2$, so that

$$
\int_{v_{1}=0}^{v_{2} / 2} f(v) v^{2} d v=f\left(v_{1}\right) \cdot\left(\frac{v_{2}}{2}\right)^{3 / 3} .
$$

This procedure is more accurate than the straight-forward scheme having $a_{1}=v_{1}^{2}\left(\frac{v_{2}-v_{1}}{2}\right)=0$. In the $\theta$ direction,

$$
\int f(\theta) \sin \theta d \theta \approx \sum_{1=1}^{I} b_{1} f\left(\theta_{1}\right),
$$


$-15-$

where

$$
\begin{aligned}
& b_{1}=\left\{\begin{array}{l}
\sin _{1}\left(\frac{\theta_{2}-\theta_{1}}{2}\right) \text { if } \theta_{1} \neq 0 \\
\theta_{2}^{2} / 8 \text { if } \theta_{1}=0
\end{array}\right\} \\
& b_{1}=\sin \theta_{1}\left(\frac{\theta_{1+1}-\theta_{1-1}}{2}\right), \quad 1<1<I \\
& b_{I}=\left\{\begin{array}{l}
\sin \theta_{I}\left(\frac{\theta_{I}-\theta_{I-1}}{2}\right) \text { if } \theta_{I} \neq \pi \\
\left(\pi-\theta_{I-1}\right)^{2} / 8 \text { if } \theta_{I}=\pi
\end{array}\right\} .
\end{aligned}
$$

Thus, the density of species "a" is computed as

$$
n_{a}=2 \pi \sum_{1, j} a_{j} b_{1} i_{a}\left(v_{j}, \theta_{1}\right) .
$$

and the energy-density of species "a" is

$$
n_{a} E_{a}=m_{a} \sum_{1, j} a_{j} b_{i} v_{j}^{2} E_{a}\left(v_{j}, \theta_{i}\right) .
$$

6. COMPUTATION OF FOKKER-PLANCK COEFFICIENTS

The collision operate, $\left(\frac{\partial f}{\partial t}\right) c$, way be written as a sum

$$
\left(\frac{\partial f_{a}}{\partial t}\right)_{=}=\sum_{b}\left(\frac{\partial t_{a}}{\partial t}\right)_{c}^{b},
$$


where $\left(\frac{\partial f}{\partial t}\right)_{c}^{b}$ represents collisions of spectes "a" with species "b".

In computing $\left(\frac{a}{\partial t}\right)_{c}^{b}$ for a general specles "b", the prosedste is that outlined in Eqs. (5) through (29), with the proviso that the sum over "o; In Eqg. (16) and (17) be replaced by the ingle index "b". The only numerical appruximations come about in the integrals of Eqs. (15) and (20) through (23). E4. (15) 13 approximated using Eqs, (41)-(43). Eqs. (20)-(23) are approximated by

$$
\int_{v_{k}}^{v_{\ell}} f(v) d v=\sum_{j=k}^{\ell-1}\left(\frac{v_{j+1}-v_{j}}{2}\right)\left(f\left(v_{j}\right)+f\left(v_{j+1}\right)\right) \text {. }
$$

A detalled explanation of the do-100, structure for the vectorized CRAY version f.s given in Appendix A.

Up to this point the assumption has been made that "b" is a "general" sopecles represented by a 2D veiocity space distribution function. Recalling that "PPAC allows flxed background Maxwellian specles in addition to general spectes, the procedure when "b" is a Maxwellian simplifies somewhat. Letting $n_{b}$ denote its density and $T_{b}$ its temperature,

$$
\left(\frac{\partial F_{a}}{\partial t}\right)_{c}^{b}=\frac{\Gamma_{a}}{v^{2}}\left(\frac{\partial}{\partial v}\left(A_{a}^{b} f_{a}+B_{a}^{b} \frac{\partial F_{a}}{\partial v}\right)+\frac{1}{\sin \theta} \frac{\partial}{\partial \theta}\left(F_{a}^{b} \frac{\partial f_{a}}{\partial \theta}\right)\right),
$$

with

$$
\begin{aligned}
& A_{a}^{b}=\left(\frac{z_{b}}{z_{a}}\right)^{2} \ln \Lambda_{a b} \frac{m_{a}}{a_{b}} n_{b}\left(-\frac{v}{v_{b}} \sqrt{\frac{2}{n}} e^{-v^{2} / 2 v_{b}^{2}}+\phi\left(\sqrt[v]{2} v_{b}\right)\right) \\
& B_{a}^{b}=\frac{v_{b}^{2}}{v} \frac{m_{b}}{m_{a}} A_{a}^{b}
\end{aligned}
$$




$$
\begin{aligned}
F_{a}^{b} & =\left(\frac{z_{b}}{z_{a}}\right)^{2} \ln \Lambda_{a b} \frac{r_{b} \sin v}{2 v}\left(\frac{v_{b}}{v} \sqrt{\frac{2}{\pi}} e^{-v^{2} / 2 v_{b}^{2}}\right. \\
& \left.+\left(1-\frac{v_{b}^{2}}{v^{2}}\right) \phi\left(\frac{v}{\sqrt{2} v_{b}}\right)\right) .
\end{aligned}
$$

Here, $n_{b}$ is the density of spectes "b", $v_{b}^{2}-T_{b} / m_{b}$, and $\phi$ is tha error function

$$
\phi(x)=2 / \sqrt{\pi} \int_{0}^{x} e^{-y^{2}} d y .
$$

For $x<0.6, \phi(x)$ is approximated by a power series:

$$
\phi(x)=\sum_{k=0}^{6}(-1)^{k} \frac{x^{2 k+2}}{k !(2 k+1)},
$$

and for $x \geq 0.6$,

$$
\phi(x)=1-\frac{2}{\sqrt{\pi}} \mathrm{e}^{-x^{2}} \sum_{k=1}^{5} A_{k} i^{k}
$$

with

$$
\pi=1 /(1+p x),
$$

$$
\begin{aligned}
& \text { and } P=0.3275911, A_{1}=0.225836846, A_{2}=-0.252128668, A_{3}=1.25969513 \text {, } \\
& A_{4}=-1.287822453 \text { and } A_{5}=0.94064607^{(10)} \text {. }
\end{aligned}
$$




\section{AUGMENTED EQUATIONS}

There are many sliuations in which it is desirable to model not only Coulomb collisicns but additional physics as well (e.8., rf heating, electric field acceleration). This is provided for to the extent that the equations to be time-advanced are of the general form (dropping species identifier "a")

$$
\begin{aligned}
& Q \frac{\partial f}{\partial t}=\frac{1}{v^{2}} \frac{\partial}{\partial v}\left(A f+B \frac{\partial f}{\partial v}+C \frac{\partial f}{\partial \theta}\right) \\
& +\frac{1}{v^{2} \sin \theta} \frac{\partial}{\partial \theta}\left(D E+E \frac{\partial f}{\partial v}+F \frac{\partial f}{\partial \theta}\right)+K f+J,
\end{aligned}
$$

where $A, B, C, D, E, F, J, K$ and $Q$ are arbitrary functions of $v$ and $\theta$. The coefficients $A, B, C, D, E, F$ include contributions from the collision operator $\left(\frac{\partial f}{\partial t}\right)$ as computed in section 6 and possible user-supplied contributions. The coet $f$ lctents $J, K$ and $Q$ are algo user-supplied, so that neutral beam infection (1) and charge exchange ( $K$ ) may be conventent'y madeled. The quanticy $Q$ is normaly equal to 1 , but it may be specified arbftrarily efther for debugging purposes or for representing a species-dependent or spatlally yarying timestep. Implepentation detalls may be found tn the source listing.

8. SPATIAL DISCRETIZATION

Spatlal derivatives are discretized as follows:

$$
\begin{aligned}
& \left.\frac{\partial}{\partial v}(A f)\right|_{1, j}=\left(A_{1, j+1} E_{1, j+1}-A_{1, j-1} E_{1, j-1}\right)^{/ 2 \Delta v_{j}} \\
& \left.\frac{\partial}{\partial v}\left(B \frac{\partial f}{\partial v}\right)\right|_{1, j}:\left\{B_{1, j+1 / 2}\left(\frac{E_{t, j+1}-E_{1, j}}{\Delta v_{j+1 / 2}}\right)\right.
\end{aligned}
$$




$$
\begin{aligned}
& \left.-B_{1, j-1 /}\left(\frac{f_{1, j}-f_{1, j-1}}{\Delta v_{j-1 / 2}}\right)\right\} \Delta v_{j} \\
& \left.\frac{\partial}{\partial v}\left(C \frac{\partial f}{\partial \theta}\right)\right|_{1, j}=\left\{c_{1, j+1}\left(\frac{f_{1+1, j+1}-f_{1-1, j+1}}{2 \Delta \theta_{1}}\right)\right. \\
& \left.-c_{1, j-1}\left(\frac{E_{1+1, j-1}-f_{1-1, j-1}}{2 \Delta \theta_{1}}\right)\right\} / 2 \Delta v_{j} .
\end{aligned}
$$

where

$$
\begin{aligned}
& \Delta v_{j \pm 1 / 2}= \pm\left(v_{j \pm 1}-v_{j}\right) \\
& \Delta v_{j}=\frac{1}{2}\left(\Delta v_{j-1 / 2}+\Delta v_{j+1 / 2}\right) \\
& \Delta v_{1}=\frac{1}{2}\left(\theta_{1+1}-\theta_{1-1}\right) \\
& B_{1, j \pm \frac{1}{2}}=\frac{1}{2}\left(B_{1, j}+B_{1, j \pm 1}\right) .
\end{aligned}
$$

The terms $\frac{\partial}{\partial \theta}(D F), \frac{\partial}{\partial \theta}\left(E \frac{\partial E}{\partial v}\right)$ and $\frac{\partial}{\partial \theta}\left(F \frac{\partial E}{\partial \theta}\right)$ are differenced analogously.

The boundary conditions must also be auproximated; their discretization depends on the time-integration technique and w1!l be discussed in a later sestion. 


\section{TIMF, DISCRETTZATION}

Eq. (55) is time-integrated using elther implictt operator splitcing, an alternating direction implicit (ADI) method, or fully implicit differencing.

Because Implicit operator splitting and ADI are so simtlar, of the tro only $A D I^{(11)}$ will be described in deta1l. This is a two-step procedure, as follows:

$$
\begin{aligned}
& Q^{n}\left(\frac{f^{n+1 / 2}-f^{n}}{\Delta t / 2}\right)=\frac{1}{v^{2}} \frac{\delta}{\delta v}\left(A^{n} f^{n+1 / 2}+B^{n} \frac{\delta f^{n+1 / 2}}{\delta v}+C^{n} \frac{\delta f^{n}}{\delta \theta}\right) \\
& +\frac{1}{v^{2} s \ln \theta} \frac{\delta}{\delta \theta}\left(D^{n} f^{n}+E^{n} \frac{\delta f^{n}}{\delta v}+F^{n} \frac{\delta f^{n}}{\delta \theta}\right)+k^{n} f^{n+1 / 2}+J^{n} \\
& Q^{n}\left(\frac{f^{n+1}-f^{n+1 / 2}}{\Delta t / ?}\right)=\frac{1}{v^{2}} \frac{\delta}{\delta v}\left(A^{n} f^{n+1 / 2}+B^{n} \frac{\delta f^{n+1 / 2}}{\delta v}+C^{n} \frac{\delta f^{n+1 / 2}}{\delta \theta}\right) \\
& +\frac{1}{v^{2} \sin \theta} \frac{\delta}{\delta \theta}\left(D^{n} f^{n+1}+E^{n} \frac{\delta f^{n+1 / 2}}{\delta v}+F^{n} \frac{\delta f^{n+1}}{\delta \theta}\right)+x^{n} f^{n+1}+J^{n}
\end{aligned}
$$

where the meshpolnt indices $1, j$ have been dropped, and where $\frac{\delta}{\delta v}$ and $\frac{\delta}{\delta \theta}$ denote the discretizations of Eqs. (56) - (59). For computational expediency, the mixed derivative terms are treated explicltly. This algorithm executes a good deal faster than a fully implicit method since several small tri-diagonal linear systems are inverted Instead of a large nine-banded system. It is generally not necessary to 1terate Eqs. (60) and (61), since the Fokker-Planck coefficients depend on Integrals of the distribution functions and therefore are slowly varyding. 
For full velocity space operation, Eqs. (60) and (61), which hold at interfor meshpo:nts, are joined by boundary value equations. Letting

$$
\begin{aligned}
& G=A f+B \frac{\delta f}{\delta v}+C \frac{\delta f}{\delta \theta} \\
& H=D f+E \frac{\delta f}{\delta v}+F \frac{\delta f}{\delta \theta},
\end{aligned}
$$

Eq. (60) is salculated as follows: At $\theta=0(1=1), \frac{1}{v^{2} \sin \theta} \frac{\delta H}{\delta \theta}$ (the second term on the right hand side) is
replaced by

$$
\left.\frac{1}{v^{2} \sin \theta} \frac{\delta \mathrm{H}}{\delta \theta}\right|_{1, j}=2 \mathrm{H}_{3 / 2, \mathrm{j}} \mathrm{n} / \mathrm{v}_{\mathrm{j}}^{2} \mathrm{O}_{3 / 2}^{2}
$$

In cases where $f$ is symmetrlc abo.t $\pi / 2$, the approximation

$$
f_{I+1, j}^{n+1 / 2}=f_{I-1, j}^{n+1 / 2}
$$

1s used, and in cases where $\theta_{I}=\pi, \frac{1}{v^{2} \sin \theta} \frac{\delta H}{\delta \theta}$ is replaced by

$$
\left.\frac{1}{v^{2} \sin \theta} \frac{\delta H}{\delta \theta}\right|_{I, j}=-2 H_{I-1 / 2, j}^{n} / v_{j}^{2}\left(\pi-\theta_{I-I / 2}\right)^{2} \text {. }
$$

At $\theta=0$ and $\pi$, the $\mathrm{C}^{\mathrm{n}} \frac{\delta \mathrm{f}^{\mathrm{n}}}{6 \theta}$ term in Eq. (60) is set to 0 . (See Eq. (33).) At $y=0$, the first term on the right hand side of Eq. $(60)$ is witcen as 


$$
\left.\frac{1}{v^{2}} \frac{\delta G}{\delta v}\right|_{1,1}=\frac{3}{v 3 / 2} C_{1,3 / 2}^{n+1 / 2}
$$

and

$$
-\left.\frac{j}{v^{2} \sin \theta} \frac{\delta H}{\delta \theta}\right|_{i, 1}=0 \text {. }
$$

where

$$
C^{n+1 / 2}=A^{n_{f} n+l / 2}+B^{n} \frac{\delta f^{n+1 / 2}}{\delta v}+C^{n} \frac{\delta f^{n}}{\delta \theta},
$$

with the $C^{n} \frac{\delta f^{n}}{\delta \theta}$ term ignored at $\theta=0$ and $\pi$ (See Eq. (33)).

Eq. (61), the second half time-step, is calculated analogoasly: At $\theta=0$ $(1=1), \frac{1}{v^{2} \sin \theta} \frac{\delta H}{\delta \theta}$ is replaced by

$$
\frac{1}{v^{2} \sin \theta} \frac{\delta 11}{\delta \theta}=2 H_{3 / 2, j}^{n+1} / v_{j}^{2} \theta_{3 / 2}^{2}
$$

and at $\theta=\pi$ (when $\left.\theta_{I}=\pi\right)$,

$$
\frac{1}{v^{2} \sin \theta} \frac{\delta H}{\delta \theta}=-2 n_{I-1 / 2, J}^{n+1} / v_{j}^{2}\left(\pi-\theta_{I-1 / 2}\right)^{2} \cdot
$$

Here, 


$$
H^{n+1}=D^{n} f^{n+1}+E^{n} \frac{\delta f^{n+1 / 2}}{\delta v}+F^{n} \frac{\delta f^{n+1}}{\delta \theta},
$$

and the $\mathrm{C}^{n} \frac{\delta \mathrm{f}}{\delta \theta}$ term in Eq. (60) is aga!n 1gnored. At $v=0$,

$$
t_{, 1}^{n+1}=\sum_{i=1}^{i} b_{i}\left(f_{1,1}^{n+1 / 2}+\frac{\Delta t}{2 L_{1,1}} \frac{3}{v_{3 / 2}^{3}} \bar{G}_{1,3 / 2}^{n+1 / 2}\right) \sum_{1=1}^{1} b_{1},
$$

where $h_{i}$ is as in Eqs. $(41)-(43)$ and

$$
\overline{6}^{n+1 / 2}=A^{n} f^{n+1 / 2}+B^{n} \frac{\delta f^{n+1 / 2}}{\delta v}+C^{n} \frac{\delta \varepsilon^{n+1 / 2}}{\delta \theta},
$$

w1th the $\frac{\delta f}{\delta 0}$ term ignored at $i=0$ and $\pi$. This procedure asgures that, in the absence of sources and losses (and If $Q \equiv 1$ ), the numerical density (Eq. (44a)) does not change from $c$ inestep to timestep. The discrete boundary conditions for the fully implicit algorithm are simllar, but actually much simpler since there is no time-splitting.

As thentioned in an earlier section, one is not restricted to full velocicy space operation; that is, one may replace a subset of the above boundary conditions by Dirichlet conditions along given curves, which are approximated by open polygons in discrete $v, \theta$ space.

The princtpal difference equations, (Eqs. (60) and (61)) and the boundary conditions (Eqs. (62) - (72) or Dirichlet conditions or a combination thereof), way be cast in the following form:

$$
\begin{aligned}
& -a_{1, j}^{n} \mathrm{~F}_{i, j+1}^{\mathrm{n}+1 / 2}+\beta_{1, j}^{n} \mathrm{E}_{1, j}^{\mathrm{n}+1 / 2}-\gamma_{1, j}^{n} \mathrm{E}_{1, j-1}^{\mathrm{n}+1 / 2}=\delta_{1, j}^{\mathrm{n}} \\
& -\varepsilon_{1, j}^{n} f_{1+1, j}^{n+1}+\mu_{1, j}^{n} f_{1, j}^{n+1}=v_{1, j}^{n} f_{1-1, j}^{n+1}=\rho_{1, j}^{n},
\end{aligned}
$$


where $a, B, \gamma, \delta, \varepsilon, \psi, v, p$ are known quantities. The indices $1, j$ range over all

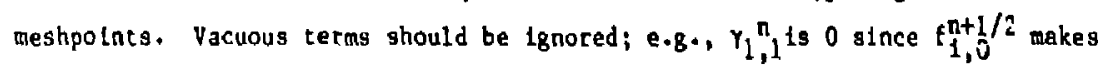
no sense. In the event of conservation boundary conditions at $y=0$, Eqs. (73) and (74), which decouple from Eq. (76), are solved after Eqs. (75) and (76).

The procedure for solving Eqs. (75) and (76) is I standard technique for solving tridiagonal systems (11). Eq. (75) is reduced to the form:

$$
f_{1, j}^{n+l / 2}=\sigma_{1, j} f_{1, j+l}^{n+l / 2}+\tau_{1, j} .
$$

where

$$
\begin{aligned}
& a_{1,1}=\left(\beta_{1, j}^{n}-\gamma_{1, j} \sigma_{1, j-1}\right)^{-1} a_{1, j}^{n} \\
& { }_{1, j}=\left(\beta_{1, j}^{n}-\gamma_{1, j}^{n} \sigma_{1, j-1}\right)^{-i}\left(o_{1, j}^{n}+\gamma_{1, j}^{n} \tau_{1, j-1}\right) .
\end{aligned}
$$

The quant 1 ties $0_{1,1}, \tau_{1, l}$ and $f_{1, J}^{n+1 / 2}$ are determined through boundary conditions. Eqs. (77) - (79) (In the CRAY version) are vectorized over the index " $i "$. Eq. (78) is reduced in an analogous manner, with vectortzation over the Index "f".

With fully impliclt differencing one obtains a system of the form

$$
\mathrm{Mi}^{\mathrm{n}+1}=\mathrm{y},
$$

where $f^{n+l}$, the distribution function at the new timestep, is viewed as a vector with I times $J$ components corresponding to meshpoints ordered rowwise or columnise. The matrix $M$ is a nine-banded matrix, a consequence of the nine point difference algorithm. The discretization at the boundary points is simliar to that for the ADI algorithm. The vector $y$ depends on the distribution function at the old timestep, $f^{n}$, and the source term $J$. Both $M$ and $y$ are computed by FPPAC, whereas it is up to the user to supply an 
algorlthw for solving Eq.=(80). The cruclal common blocks, however, are compatible with those of the ILUCG package of Shestakov ${ }^{(4)}$, and implementation of ILUCG is consequently extremely simple.

10. ENERGY TRANSFER

The rate of energy transfer to (or from) each general spectes is computed. The rate of energy-density gained by spectes "a" due to collistons with specles " $b$ " 1s equal to the second moment of the operator which represents collisions between "a" and "b":

$$
\begin{aligned}
Q_{a b} & =\pi w_{a} \int\left(\frac{\partial E_{a}}{\partial t}\right)^{b} v^{4} \sin \theta d v d \theta \\
& =-2 \pi m_{a} \Gamma_{a} \int \sin \theta d \theta \int G_{a}^{b} v d v,
\end{aligned}
$$

where $G_{a}^{i}$ is that portion of $\mathrm{C}_{a}$ (see Eq. (6)) which depends on spectes "b"; l.e., In Fgs. (16) and (17) the sum over "b" is replaced by "b" Itself, (Note that the $\frac{d H_{a}}{\partial \theta}$ term in Eq. (5) dnes nor contribute to energy transfer.) In the case where spectes "b" is Isotropic, Eq. (81b) reduces to

$$
\begin{aligned}
& Q_{a b}=-(4 \pi)^{2} m_{a} \Gamma_{a}\left(\frac{z_{b}}{z_{a}}\right)^{2} \ln A_{a b} . \\
& \int v d v \cdot\left(\frac{m_{a}}{m_{b}} N_{0}\left(E_{b}\right) f_{a}+\frac{1}{3}\left(\frac{E_{0}\left(E_{b}\right)}{v}+v^{2} \mu_{0}\left(f_{b}\right)\right) \frac{\partial f_{a}}{\partial v}\right),
\end{aligned}
$$

and furthermoce if $f_{b}$ is Maxwellian with temperature $T_{b}$, 


$$
\begin{aligned}
& Q_{a b}=(4 \pi)^{2} m_{a} r_{a}\left(\frac{I_{b}}{z_{a}}\right)^{2} \ln \Lambda_{a b} \cdot \\
& \int N_{0}\left(f_{b}\right)\left(\frac{m_{a}}{\pi_{b}} v f_{a}+\frac{T_{b}}{m_{b}} \frac{\partial f_{a}}{\partial v}\right) d v,
\end{aligned}
$$

with $M_{0}\left(f_{b}\right), N_{0}\left(f_{b}\right)$ and $E_{0}\left(E_{b}\right)$ as defined in Eqs. $(20),(21)$, and $(23)$.

\section{STRUCTURE OF PACKAGE}

FPPAC is presented as part of a complete code with driver. The driver (MAIN) first calls INITIAL, which reads in and intiallzes certain package and drtver variables needed by the program. (A superscrlpt "d" here indicates that the subroutine is part of the driver section of the code whereas a superscript "f" indicates that the routine is propelily part of the FPrAC core.) Besldiss reading in daca, INITIAL ${ }^{d}$ calls several subroutines:

(a) SETPARS $^{\text {f }}$-- coples values in PARAMETER statements into COMMON starage.

(b) XINIT ${ }^{d}$-- sets up spatlal mesh.

(c) XINITL -- computes constants and constant arrays

(d) FINIT ${ }^{d}$ - Initializes distribution functions.

(e) SOURCEE ${ }^{d}$-- calculates velocity-space sources.

(f) GNANDE $E^{\mathrm{d}}-$ computes densities and energles.

The Initfalization phase ends with a call to EEPRINT', which prints out vartous Information Including the distribution functions.

The next function of the driver is to solve the Fokker-Planck operator for NSTOP time steps. This is carried out through calls to three controlling package routines -- SEIITUP ${ }^{f}$, which sets up variables; COEF $\mathrm{f}^{\mathrm{f}}$, which computes the Fokker-Planck operator, and XSWEEP ${ }^{f}$ (or XSWEEPI ${ }^{*}$ ), which time-advances the distribution functions. Detalls follow. 
(a) SETITUP ${ }^{f}$-- SETITUP first calle PREPKGl ${ }^{\mathrm{f}}$, aser-supplled (blank) rout Ine which the uger may flll in for the purpose of varying boundaty conditiors and miscellaneous package varlables. (The procedures which nust be followed in order to 1111 in PREPKGl and other user-suppl led (blank) routines are given in fnclusive detall in the comments at the beginning of the source code under the heading "User Responsibtlitles.") GNaNDS (also a b] ank routine) then coples the densitles and energies from user arrays into package arrays. The Coulomb logarithms are then computed In GAMAI ${ }^{f}$, A blank routine SETMOD $f$ is provided in the event the user whahes to modify the Coulomb logarithws. This might be desirable for the purpose of simulating ada..tionsl physics or dehugging.

(b) $\mathrm{COEF}^{\mathrm{F}}$-- The procedure here is to compute for each species (firat Maxwellians and then general spectes) its contribution to the collision operators of all of the general species. The energy transfer rates, which are merely second moments of the collision operators, are computed in ENTRNS ${ }^{\mathrm{f}}$, Other routines used are:

(I) $\operatorname{DISTS}^{f}$ (a blank routine), which coples the distribution functions from user storage into package storage;

(2) $\operatorname{CoSTR}^{f}$, which stores or recovers contributions from a given general spectes to the collision operator (optlonal);

(3) $E R F^{f}$, which computes the error function.

(c) XSWEEP ${ }^{f}$-- Each general spectes is time-edvanced using either ADI or Implicit operator splitting. First, a package subroutine BNDEXT ${ }^{f}$ determines the extreme edges of the plasma doma1n. Additional physics terms are added to the Fokker-planck operator in the blank rout ine FPSETUP ${ }^{f}$. The distribution function is transfered from user atorage to package storage in the blank routine DISTS ${ }^{f}$. Routine DGNSTK ${ }^{f}$ (also blank) computes diagnostic quantitites prior to time-advancement. The Eirst half-time-step is then carried out. If ADI is used, the explicit contributions to the discretized operator are computed in GETDH ${ }^{\mathrm{f}}$. A 
package-routine DGNSTK ${ }^{\mathrm{f}}$ is called for a gecond time in order to compute diagnostics which depend on the half-time-gtep distribution function. The second half-time-step is now carried out. If ADI 18 used, the explicit contributions to the discretized operator are computed in GETDG ${ }^{f}$. DGNSTK is called for a chird and final time. Finally, the updated distribution function is transferred from package storage to user storage in the blank routine DISTS2 ${ }^{\mathrm{f}}$.

(c') XSWEEPt ${ }^{f}$-- Each general specles is prepared for time-advancement using a fully implictt (backward Euler) algortthm. Routines BNDEXT ${ }^{f}$, FPSETUP ${ }^{f}$, DISTS ${ }^{f}$ and DGNSTK ${ }^{f}$ are called as in XSWEEP ${ }^{\mathrm{E}}$. The augmented matrix for the fully implicte system is computed in COIMPL ${ }^{f}$, In order to solve the banded system, the user must f 111 in blank subroutine IMPSOLV ${ }^{\text {. }}$ Routines DCNSTK ${ }^{f}$ and DISTS2 ${ }^{f}$ are then called, as above.

After all of the diatribution functions have been advanced, an auxliliary driver routine CHPDST ${ }^{d}$ is called. This routine, which is used only for test problem number 2, adds the contribution of "passing electrons" (see below) to the election distribution function array. The MAIN loop is concluded with calls to GNANDE and EEPRINT (described earliez). After NSTOP timesteps, the driver ends with a final call to EEPRINT ${ }^{\text {. }}$.

Complete lists of driver and package routines appear in Tables 1 and 2.

TABLE I -- DRIVER ROUTINES

INITIAL XINIT FINIT

GNANDE SOURCE EEPRINT

CHPDST 


\section{TABLE 2 -- PACKAGE ROUTINES}

$\begin{array}{lll}\text { BNDEXT } & \text { COEF } & \text { COIMPL } \\ \text { COSTR } & \text { ENTRNS } & \text { ERF } \\ \text { GANMAI } & \text { GETOH } & \text { GETDG } \\ \text { SETITUP } & \text { SETPARS } & \text { XINITL } \\ \text { XSWEEP } & \text { XSWEEPI } & \text { FPSETUP } \\ \text { DGNSTK } & \text { DISTS } & \text { DISTS2 } \\ \text { GNANDS } & \text { IMPSOLV } & \text { PREPKGI } \\ \text { SETMOD } & & \end{array}$

12. LIBRARY SUBROUTINES

EPPAC makes use of several library and inline subprograms which reside on the National MFE Computer Center (MFECC) network. For the benefit of users on cther systems, these routines, which on the MMFECC network are vectorized, are located toward the end of the source deck. Clearly, they should be deleted by NMFECC users. In fact, in the case of the function "CVMGM", CFT compller users must delete the FORTRAN coding in the source if the program is to run correctly. A table of these routines follows:

\section{TABLF. 3 LIBRARY ROUTINES}

\begin{tabular}{lll} 
Routine & Machine & Nat1onal MFE Origin \\
\cline { 2 - 3 } BCAST & Cray,7600 & FORTLIB \\
SCOPY & Cray & VECLIB \\
SSCAL & Cray & VECLIB \\
CUMGM & Cray & CFT Comp1ler - In 11ne \\
QVCOPY & 7600 & STACKLIB \\
QVSET & 7600 & STACKLIB \\
QWMPY1 & 7600 & STACKLIB \\
QMA2 & 7600 & STACKLIB \\
QACOPY & 7600 & STACKLIB \\
QWMPY0 & 7600 & STACKLIB
\end{tabular}




$\begin{array}{lll}\text { QVADDO } & 7600 & \text { STACKLIB } \\ \text { LINK* } & \text { Cray, } 7600 & \text { FORTLIB }\end{array}$

13. COMMON VARIABLES

Al1 relevant COMMON variables are described in the source listing. Those variables in COMNON blocks NPARAMl, NPARAM2, NPARAM3, NTEMP, and ITEMP are described in detall. Variables in COMHON blocks NXIN1, NXIN2, NXIN3, MTEMP, MCOEF, NVALSI and NVALS2 are generally worker variables which the user need not access (an exception is the pair af varlables TERN1 and TERN2 in block NWALS1, which are described in User Responstbility No. 7).

14. ADDITIONAL PHYSICS

In order to present meaningful test problemis, additional physics terms are Included, as follows:

(a) Particle Source

To the right hand side of Eq. (1) 1s added a term

$$
s_{a}=\bar{a}_{a} e^{-\bar{b}_{a}}\left(v-B_{a}\right)^{2} v^{2}-\bar{c}_{a}\left(\cos \theta-a_{a}\right)^{2},
$$

where $\bar{a}_{a}$ (which defies $B_{a}$ by means of $\bar{a}_{a}=\frac{1}{2} m_{a} \beta_{a}{ }^{2}$ ), $\bar{\sigma}_{a}, \bar{c}_{a}$ and $\bar{d}_{a}$ are input constants, and where $\bar{a}_{a}$ is chosen so that the source current equals $J_{a}$, also an input constant. The quartity $\tilde{v}$ is a velocity normalization constant which is also input.

*This routine sets ug input/output and does not appear in the source deck. 


\section{(b) Particle Loss}

To the rlght hand side of Eq. (1) Is added a term

$$
L_{a}=-f_{a} / t_{a},
$$

where

$$
\tau_{a}=\tau_{0 a}+\tau_{1 a}(v / v)^{3}
$$

Th1s loss fime increases roughly as energ; to the three-halves power.

\section{(c) RF Heating}

To the right hand slde of $\mathrm{Eq} .(1)$ is added a term

$$
\begin{aligned}
& R_{a}=D_{a}\left(\frac{1}{v^{2}} \frac{\partial}{\partial v}\left(v^{2} \sin \theta \frac{\partial f_{a}}{\partial v}+v \sin \theta \cos \theta \frac{\partial E_{a}}{\partial \theta}\right)\right. \\
& \left.+\frac{1}{v^{2} \sin \theta} \frac{\partial}{\partial \theta}\left(v \cos \theta \sin ^{2} \theta \frac{\partial f_{a}}{\partial v}+\sin \theta \cos ^{2} \theta \frac{\partial f_{a}}{\partial \theta}\right)\right\} .
\end{aligned}
$$

"ere $D_{a}$ is of the form $D_{o a} \exp \left(-v^{2} / c^{2}\right)$, which reflects the fact that $r f$ has a smaller effect on the higher energy particles (the If term is applied to electrons in Test problem 1).

\section{(d) Intitial Distrizution Functions}

Intially, $\mathrm{f}_{\mathrm{a}}$ is of the form

$$
f_{a}=a_{a} e^{-b} a\left(v-a_{a}\right)^{2} / v^{2}-c_{a}\left(\cos \theta-a_{a}\right)^{2}
$$


where $a_{a}$ (which defles $\beta_{a}$ by means of $\left.a_{a}-\frac{1}{2} a_{a} \beta_{a}^{2}\right), b_{a}, c_{a}$ and $d_{a}$ are input constants, and where $a_{a}$ is chosen so that the inttial density equals $n_{a}$, also an Input constant.

\section{(e) Partial Velocity Domain Opttion (Spectes "1" Only)}

It 1s assumed here that the general species are in the presence of a confining wagnetıc fleld and ambipolar potential. The domain of intarest for spectes "l" is $0 \leq \theta \leq \pi / 2,0 \leq v \leq v_{m}(\theta)-v_{c}\left(1-R \sin ^{2} \theta\right)^{-1 / 2}$, where $R$ is the mirror rat to $(0<R<1)$ and $v_{c}{ }^{2}-2 / e \phi / / m_{1}$, being the plasma potential and $m_{1}$ the mass of species " 1 ".

\section{(f) Passing Particles Option (Spectes "l" On'y)}

This option may be used only in confunction with the above Partial Velocity Domain option. It is assumed that there is a truncated Maxwellian distribution function of "passing particles"; 1.e., for $v \geq v_{m}(\theta)$,

$$
f_{l}(v, \theta)=n_{u}\left(\frac{m_{l}}{2 \pi T_{u}}\right)^{3 / 2} e^{-m_{l} v^{2} / 2 T_{u}}
$$

where $\pi_{u}$ and $E_{u}=3 / 2 T_{u}$ are input constants. When this option is used, the initial distribution function of confined particles must also be a truncated Maxwellian (but not necessartly of the same density and temperature); 1.e., $a_{l}=c_{1}=d_{1}=0$ and $b_{1}$ is inversely proportional to the desired temperature.

15. PACKAGE INPUT AND OUTPUT

The package FPPAC (as opposed to the package plus driver) contains no READ or WRITE statements. AlI Input and output is transmitted between the package and driver via Cormon blocks and blank subroutines which the user must fill in. An extensive $I / 0$ description is contained in the comments in the source code under "User Responsib1lities". 
16. DRIVER INPUT AND OUTPUT

Data is read in on logical unit 2 and is written out on logical unft 3. Assignment of these channels for MMFECC users is accomplished in the CALL LINK statement, which is the first executable statement in the driver. The input data disc file is given the name INTLONS and the printed output flle is assigned the name FPOUT. There ate also several paramecers which are aet at complle time via pardMETER statements. Tables of input varlables follok. For further clarffication users should refer to the seation in which the tegt problems are described.

\section{TABLE OF PARAMETERS}

$\begin{array}{ll}\text { PARAMETER } & \text { Description } \\ J X & \text { Number of points in } v \text { mesh } \\ \text { IY } & \text { Number of points in } \theta \text { mesh } \\ \text { NBO } & \text { Number of general spectes } \\ \text { MEQ } & \text { Number of Maxwellian ion species } \\ M X & \text { Highest order Legendre polynomial in } \\ & \text { expansion for Rosenbluth potentials } \\ \text { KSYDM } & 0 \text { for assumed symmetry about } \\ & \theta=\pi / 2 ; 1 \text { otherwise } \\ M E X & 1 \text { if electrons are a general species } \\ & 0 \text { if electrons are a Maxwellian species }\end{array}$

TABLE of DATA CARD (UnIt 2) VAKIABLES

$\begin{array}{ll}\text { Vartable } & \text { Description } \\ \text { ITEST } & 1 \text { for test problem } 1 \\ & 2 \text { for test problem } 2 \\ \text { NSTOP } & \text { Number of time steps } \\ \text { NPRINT } & \text { Frequency of print-auts }\end{array}$




$\begin{array}{ll}\text { NCOEF } & \begin{array}{l}\text { Frequency of computation of Fokker-Planck } \\ \text { coefflcients }\end{array} \\ \text { XMAX } & \text { Niaimum normalized velocity } \\ \text { DTR } & \text { Timestep (seconds) } \\ \text { VNORM } & \text { Velocity normalization constant } \dot{v} \\ & \text { (cu/sec) (XMAX * VNORM - maximum ion or electron speed } \\ & \text { represented on velocity mesh) }\end{array}$

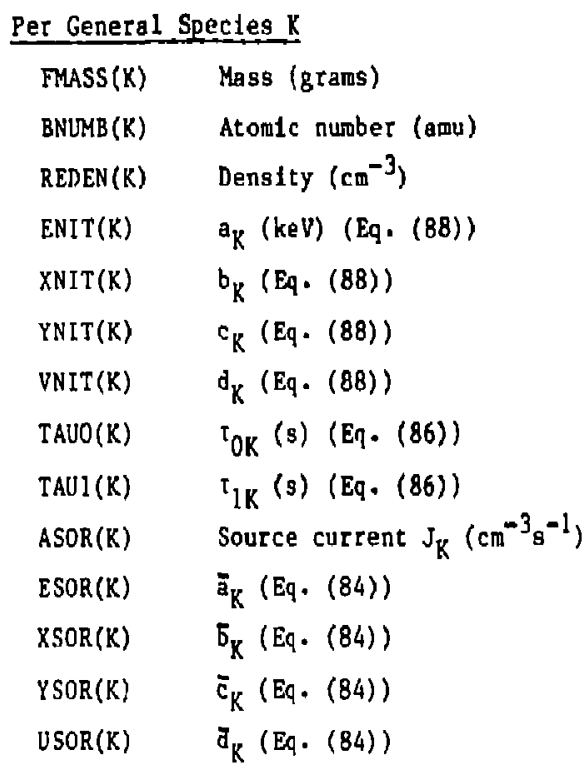

\section{Per Maxwellian Species $\mathrm{K}$}

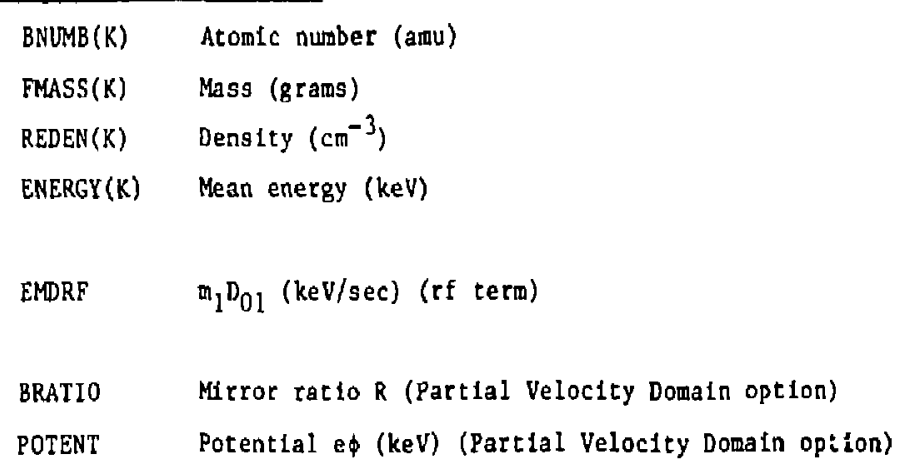




\section{$-35-$}

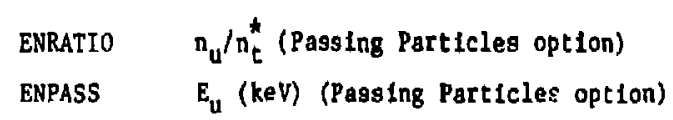

The output consists of:

(a) A listing of the PARAMETER and logical unit 2 vartables (at time $t=0$ only).

(b) The general species normalized distribution functions (every NPRINT time steps). The normalization is as described online (see note following Eq. (3) In listing) with BNORM(K) equal to the Initial density of species $R$. Also, the densitles and mean energles of the general species are printed out.

17. DESCRIPTION OF TEST FROBLAMS

Because of the highly versatile nature of this package, two test problems are presented.

\section{TEST PROBLEM I}

Problem 1 describes a toroldal system in which neutral $D^{\circ}$ and $T^{\circ}$ beams are injected tangentially, but in opposite directions (12). Low energy lons are assumed to leave the system through radial diffuston. The equation to be solved is

$$
\frac{\partial f_{k}}{\partial t}=\left(\frac{\partial f_{k}}{\partial t}\right)_{c}+s_{k}+L_{k},
$$

where "k" indexes $\mathrm{D}^{+}$and $\mathrm{T}^{+}$. Cullistons accur between all charged spectes including fixed Maxwellian electrons at a temperature $T_{e}$ and density $n_{e}$.

${ }^{n_{t}}{ }_{t}$ is the full velocity-space density of the confined Maxwelliar $a_{1} \exp \left(-b_{1}\right.$ $v^{2} / v^{2}$ ) (see Eq. (B8) and the above section describing the Passing Particles option.) 
A table of input varlables follows:

\section{INPUT VARIABLES FOR TEST PROBLEM 1}

$\begin{array}{ll}\text { JX } & 71 \\ \text { IY } & 31 \\ \text { NBO } & 2 \\ \text { MEQ } & 0 \\ \text { MX } & 4 \\ \text { KSYDM } & 1 \\ \text { MEX } & 1\end{array}$

ITEST

NSTOP $\quad 1000$

NPRINT 250

NCOEF 1

XMAX 1.

DTR $(\Delta \mathrm{t})$

VNORN $(\bar{v})$

$\operatorname{FMASS}(1) \quad\left(m_{D}\right)$

$\operatorname{BNUMB}(1) \quad\left(z_{D}\right)$

$\operatorname{REDEN}(1) \quad n_{D}(t=0)$

ENIT(l) $a_{D}$

$\operatorname{XNIT(1)} b_{D}$

YNIT(1) $C_{D}$

$\operatorname{VNIT(1)} \mathrm{d}_{D}$

TAUO(1) To0

TAUL(1) TID

ASOR(1) $\mathrm{J}_{\mathrm{D}}$

$\operatorname{ESOR}(1) \quad a_{D}$

$\operatorname{XSOR}(1) \quad \sigma_{D}$

YSOR(1) $\bar{c}_{D}$

$\operatorname{USOR}(1) \bar{d}_{D}$

FMASS (2) $\quad n_{T}(c=0)$
$8 . \times 10^{-3} \mathrm{~s}$

6. $\times 10^{8} \mathrm{~cm} / \mathrm{s}$

1

1

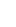

4

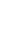

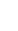

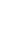

50

1.$$
\text { 6. } \times 10^{8} \mathrm{~cm} / \mathrm{s}
$$$$
3.3433 \times 10^{-24} \mathrm{gm}
$$$$
1 .
$$$$
3.4 \times 10^{13} \mathrm{~cm}^{-3}
$$

40. $\mathrm{keV}$

100.

10.

1.

$0.025 \mathrm{~s}$.

200. $s$.

$6.5 \times 10^{13} \mathrm{~cm}^{-3} \mathrm{~s}^{-1}$

99. keV

940.

275.

1.

$5.01495 \times 10^{-24} \mathrm{gm}$ 


\begin{tabular}{|c|c|}
\hline $\operatorname{BNOMB}(z) \quad\left(z_{T}\right)$ & 1. \\
\hline $\operatorname{REDEN}(2) \quad n_{T}(t=0)$ & $3.4 \times 10^{13} \mathrm{~cm}^{-3}$ \\
\hline $\operatorname{ENIT}(2)$ & 45. keV \\
\hline $\operatorname{XNLT}(2)$ & 100. \\
\hline YNIT(2) & 10. \\
\hline VNIT(2) & -1 \\
\hline TAUO(2) & 0.0258. \\
\hline TAUI(2) $T_{1 T}$ & $200 . \mathrm{s}$ \\
\hline $\operatorname{ASOR}(2) \quad J_{T}$ & $6.5 \times 10^{13} \mathrm{~cm}^{-3} \mathrm{~s}$ \\
\hline$E S O R(2)$ & 149. keV \\
\hline $\operatorname{XSOR}(2)$ & 1400. \\
\hline YSOR $(2) \quad \bar{c}_{T}$ & 235. \\
\hline $\operatorname{USOR}(2) \quad \pi_{T}$ & -1. \\
\hline $\operatorname{BNUMB}\{3\}$ & 1 \\
\hline $\operatorname{EMASS}(3) \quad\left(m_{\mathrm{e}}\right)$ & $9.1066 \times 10^{-28} \mathrm{gm}$ \\
\hline $\operatorname{REDEN}(3) \quad\left(n_{\mathrm{e}}\right)$ & $7 . \times 10^{13} \mathrm{~cm}^{-3}$ \\
\hline ENERGY(3) (3/2T $\mathrm{e})$ & 8. keV \\
\hline EMDRF $\left(m D_{0}\right)$ & 0. \\
\hline
\end{tabular}

Eq. (90) is time-integrited using implicit operator splitting. Within eight seconds $(t=8 \mathrm{~s}$ ) an approximate steady state is reached. The deuteron and triton densities are $7.29 \times 10^{13} \mathrm{~cm}^{-3}$ and $5.27 \times 10^{13} \mathrm{~cm}^{-3}$, respectively. The corresponding mean energles are $36.4 \mathrm{keV}$ and $44.1 \mathrm{keV}$.

A simplifled verstion of this rest problem consists of allowing the initial detteron and triton distribution functions to relax to (approximate) Maxwellians at the electron cemperature $T_{e}$. This may be accomplished by serting the source currents (ASOR) equal to 0 and the confinement $t$ imes (TAUO) equal to $10^{90}$ (effectively infinity). An even simpler case is obtained by eliminating the tritons and electrons completely and allowing the deuterons to relax to a Maxwellian. Here the triton densicy (REOEN(2)) and electron iensity (KEDEN(3)) should be set to $10^{-90}$ (effectively 0 ). 


\section{TEST PROBLEM 2}

Problem 2 simuistes a tandem atror system (13). The package solves for the distribution function of trapped electrons in the presence of passing electrons and a confinting magnetic fleld and plasma potential (14). The electrons undergo self-collisions, colligions wh a flxed Kaxvelilan ion background of density $a_{1}$ and temperature $T_{1}$, and are further accelerated by an if heating term. The effect of the passing electrons is to dictate the value of the electron distribution function along an outer boundary in velocity space.

The equation to be solved is

$$
\frac{\partial E_{e}}{\partial t}=\left(\frac{\partial E_{e}}{\partial t}\right)_{c}+R_{e},
$$

where $f_{e}$ is the $t$ apped electron distribution function and the latter term describes $r$ ff dffusion perpendicular to the magnetic field (see Eo. (87)). Boch the Partial Velocity Drimin and Passing Particles options are utilized.

In describing the Input, it is convenlent to define a quantity $Y(T)$. Given a Maxwellian of temperature $T, Y(T)$ represents the fraction of particles within the velocity space domain $v \leq v_{m}(\theta)$. The dependence on mitror ratio $R$ and potential e $\phi$, though not explicitly stated, is implied (See Partial Vr:ocity Domain option).

Both the trapped electrons and passing electrons are stored in the same array. The inftial density of this composite distribution function is

$$
n^{*}=n_{t} \gamma\left(T_{t}\right)+n_{u}\left(1-Y\left(T_{u}\right)\right),
$$


where $n_{t}$ and $T_{t}$ are the full-veloctty-space density and temperature of trapped electrons and $n_{u}$ and $T_{u}$ are the full-velocity-space density and temperature of passing electrons. The quantities $n^{*}$ (REDEN(1)) and $n_{u} / n_{t}$ (ENRatio) are Input (as opposed to $n_{t}$ and $n_{u}$ themselves). Also input are the quantities $E_{u}=3 / 2 T_{u}$ (ENPASS) and $b_{1}(X N I T(1))$, which is related to $t_{t}$ via

$$
T_{t} \text { (ergs) }=\frac{1}{2} m_{l} \nabla^{2} / b_{1}
$$

Density and energy printouts Include the contributions due to the passing e lectrons.

The Input variables for this problem are as follows:

\section{INPUT VARIABLES FOR THE IEST PROBLEM 2}

\begin{tabular}{|c|c|}
\hline$J X$ & 101 \\
\hline IY & 20 \\
\hline NBO & 1 \\
\hline MEQ & I \\
\hline $\operatorname{Mx}$ & 8 \\
\hline KSYDM & 0 \\
\hline $\operatorname{MEX}$ & 0 \\
\hline ITEST & 2 \\
\hline NSTOP & 30000 \\
\hline NPRINT & 7500 \\
\hline NCOEF & 100 \\
\hline $\operatorname{xan} x$ & so. \\
\hline $\operatorname{DTR}(\Delta t)$ & 2. $\times 10^{-4} \mathrm{~g}$ \\
\hline WNORH (Ũ) & $6 . \times 10^{8} \mathrm{~cm} / \mathrm{s}$ \\
\hline $\operatorname{FMASS}(1) \quad\left(m_{e}\right)$ & $9.1066 \times 10^{-28} \mathrm{gm}$ \\
\hline $\operatorname{BNOMB}(1) \quad\left(z_{e}\right)$ & 1. \\
\hline $\operatorname{REDEN}(1) \quad\left(\mathrm{Eq}_{\mathrm{q}},(92)\right)$ & $7.33 \times 10^{12} \mathrm{cos}^{-3}$ \\
\hline $\operatorname{ENIT}(1) \quad(a)$ & 0. \\
\hline
\end{tabular}




\begin{tabular}{|c|c|}
\hline $\operatorname{XNIT(1)\quad (b)~}$ & $5.116 \times 10^{-3}$ \\
\hline $\operatorname{YNIT}(1) \quad(c)$ & 0. \\
\hline $\operatorname{VNLT}(1) \quad$ (d) & 0 \\
\hline TAUD $(1)^{*}$ & $1 . \times 10^{90} \mathrm{~s}$ \\
\hline TAUl(1)* & $1 . \times 10^{90} \mathrm{~s}$ \\
\hline $\operatorname{ASOR}(1) *$ & $0 . \mathrm{cm}^{-3} \mathrm{~s}^{-1}$ \\
\hline $\operatorname{ESOR}(1) *$ & 30. keV \\
\hline $\mathrm{XSOR}(1) *$ & 10. \\
\hline $\operatorname{YSOR}(1) *$ & 0. \\
\hline $\operatorname{USOR}(1) *$ & 0. \\
\hline $\operatorname{BNUMB}(2) \quad\left(z_{1}\right)$ & 1. \\
\hline $\operatorname{EMASS}(2) \quad\left(\mathrm{m}_{1}\right)$ & $3.3433 \times 10^{-24} \mathrm{gm}$ \\
\hline $\operatorname{REDEN}(2) \quad\left(n_{1}\right)$ & $7.33 \times 10^{12} \mathrm{car}^{-3}$ \\
\hline $\operatorname{ENERGY}(2) \quad\left(3 / 2 \mathrm{~T}_{1}\right)$ & 305. keV \\
\hline ENDRF $\left\langle m_{e} D_{0}\right\rangle$ & 60. $\mathrm{keV} / \mathrm{s}$ \\
\hline BRATIO (R) & 0.4 \\
\hline POTENT $(e \phi)$ & 60. keV \\
\hline ENRATIO $\left(n_{v} / n_{t}\right)$ & 12.16 \\
\hline ENPASS $\left(3 / 2 T_{u}\right)$ & $13.5 \mathrm{keV}$ \\
\hline
\end{tabular}

*Irrelevant for this problem. See Test Problem 1

The Fokker-Planck equation Including of is then time-Integrated uging implicit operator splitting. Within six seconds $(t=6 \mathrm{~s})$ an approximate steady-s"ate is reached. The total electron density (trapped plus untrapped) is $2.21 \times 10^{12} \mathrm{~cm}^{-3}$ and the mean energy is $32.3 \mathrm{keV}$, which is constderably higher than the $13.5 \mathrm{keV}$ energy of the passing electrons a.one. 
References

1. J. Killeen, A.A. Mirin, and M.E. Rensink, "The Solution of the Kinetic Equations for a Mult1specles Plasma," in Methods in Computational Physics 16. Academic Press (1976), 389.

2. J. Killeen and A.A. Mirin, "Nugerical Solution of the Fokker-Planck Equations for a Multispecles Plasma", in College in Theoretical and Computational Plasma Physics, Trieste (1977), IAEA, Vlenna, 27.

3. M.G. McCoy, A.A. Mirin, and J. Killeen, "A Vector 1zed Fokker-Planck Package for the CRAY-1", Sclent if ic Computer Exchange Meeting, Livermore (1979), UCRL-83206.

4. A.I. Shestakov, "Users Manual for ILUCG," Laurence Livermore Laboratory Internal Document UCID-18560 (1980).

5. M.N. Rosenbluth, W.M. MacDonald, and D.L. Judd, "Fokker-Planck Equation for an Inverse Square Force," Phys, Rev, 107, No, 1 (1957), I.

6. A.A. Mirin, "Hybrld II--A Two Dimensional Multispecies Fokker-Planck Computer Code," Lawrence Livermore Laboratory Report VCRL-51615, Rev. 1 (1975).

7. R.H. Harvey, J.C. Riordan, J.L. Luxon, and K.D. Marx, "Studles of Current Due to RF Induced Runaway in the DIIA Lower Hybrid Experdment," Annual Controlled Fusion fineory Conf., Mount Pocono (1979), IC43.

8. A.A. Mirin, J. Killeen, K.D. Marx, and M.E. Rensink, "A Radial Transport/Fokker-Planck Model for a Tokamak Plasma," J. Comp. Phys. 23, No. I $(1977), 23$.

9. A.A. Mirin, I.B. Bernstein, R.H. Cohen, and M.E. Rensink, "Fokker-Planck Studies of the Interaction Between Trappped and Untrapped Electrons in hagnetic Mirrors," Annual Controlled Fusion Theory Conf., Tucson (1980), $2 \mathrm{~A} 2$.

10. C, Hastings, Jr., "Approximations for Digltal Computers," Princeton Universicy Press, Princeton (1955).

11. R.D. Richtnyer and K.W. Morton, "Difference Methods for Initial Value Problems," Wiley, New York (1967). 
12. A.A. M1rin and D.L. Jassby, "Fokker-Planck/Transport Studies of the Tokamak Fusion Test Reactor," IEEE Transactions on Plasma Sclence (1980), to appear.

13. T.K. Fowler and B.G. Logan, Comments on Plasma Physlcs and Controlled Fusion 2 (1977), 167.

14. M.E. Rensink, A.A. Mirin, and R.H. Cohen, to be published.

\author{
Mor I IIIIFH
}

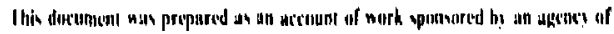

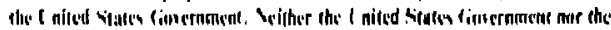

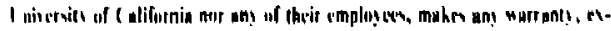

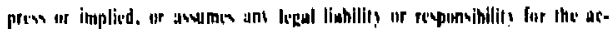

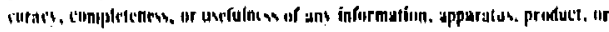

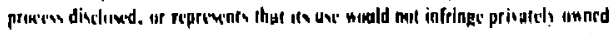

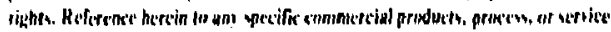

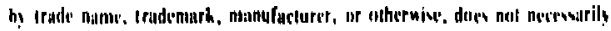

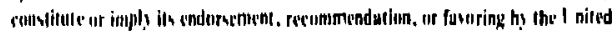

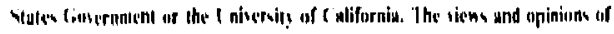

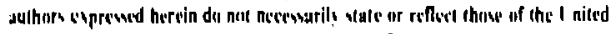

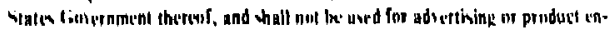
dursentint purpiars. 


\section{Appendix A}

\section{Computation of Fokker-Planck Coeff1cients on the C:1Y-1 Computer}

Since the structure of each of the six coefficients is quite similar, the detalled evaluation of only one of them, namely $C_{B}($ see $E q .(10))$, is considered.

Letting

$$
\begin{gathered}
\tilde{c}_{l}^{b}\left(v_{j}, \theta_{1}\right)=-\frac{1}{2 v_{j}} B_{l}^{b}\left(v_{j}\right) \frac{\partial}{\partial \theta} D_{l}\left(\cos \theta_{1}\right) \\
+\frac{1}{2} \frac{\partial}{\partial v} B_{l}^{b}\left(v_{j}\right) \frac{\partial}{\partial \theta} P_{l}\left(\cos \theta_{l}\right),
\end{gathered}
$$

$r$ may be expressed (using Eq̣s. (10) and (16)) in terms of the vartous $c_{l}^{b}$ coefficients as

$$
c_{a}\left(v_{j}, \theta_{i}\right)=\sum_{b} \ln A_{a b}\left(\frac{z_{b}}{z_{a}}\right)^{2} \sum_{l=0}^{M} \tilde{c}_{l}^{b}\left(v_{j}, \theta_{1}\right) .
$$

Note that the Legendre sertes is truncated at M+I polynomlals. Coeffictents $\tilde{A}_{\ell}^{b}$ through $\tilde{F}_{\ell}^{b}$ may be sintlarly deflined and expressed.

The expressions for the coefficients $\tilde{A}_{\ell}^{b}$ through $\tilde{F}_{\ell}^{b}$ are complicated (e.g. Eq. Al) and these coefflclents must be evaluated at all of the mesh points. In fact, the computation of these coefficients represents a high percentage of the total number of arithmetic operations required; consequently, it is necessary to calculate these coefficients as rapldly as possible. This is accomplished through a sertes of nested "do-loops" which the CRAY FORTRAN (CFT) compller vectorizes. 
The coefficients $\tilde{A}_{\ell}^{b}\left(v_{j}, \theta_{1}\right)$ through $\tilde{F}_{\ell}^{b}\left(v_{j}, \theta_{1}\right)$ are functions of the four Indices, "b", "q", " $\mathrm{f}$ " and " $\mathrm{l}$ ", and efficiency considerations dictate that the specles Index "b" and the Legendre Index " $\ell$ " form the outer-most "do-loops", since " $b$ " and " $\ell$ " are never large. W1thin these two loops one must evaluate Eq. (Al) for all $\left(v_{j}, \theta_{i}\right)$ mesh points. The procedure way be outlined as follows:

(1) Calculate the Legendre coefficients $\left(v_{\ell}^{b}\left(v_{j}, t\right)\right\} \underset{j=1}{\mathrm{~J}}\left(\mathrm{Eq}_{q} \cdot(15)\right)$. This involves the calculation of J 1-D Integrals over $\theta$, and may be calculated in two nested loops with the outermogt loop over $\theta$ ("I"). Th1s will permit compller vectorization of the entire procedure, since the inner loop over $v$ ("j") is not recursive.

(2) Evaluate the functionals $\left\langle M_{\ell}\left(v_{\ell}^{b}\right)\left(v_{j}\right), N_{\ell}\left(v_{l}^{b}\right)\left(v_{f}\right), R_{\ell}\left(v_{\ell}^{b}\right)\left(v_{j}\right)\right.$, $\left.E_{\ell}\left(V_{\ell}^{b}\right)\left(v_{j}\right)\right\} \underset{j=I}{J}$ (See Eqs. (20) - (23)). This is accomplighed in two separate loops over " $j$ ". For the functional $N_{l}\left(v_{l}^{b}\right)\left(v_{j}\right)$, the first loop calculates the rempuiary array TEM $(j)=v_{l}^{b}\left(v_{j}\right) v_{j}(2+l) \Delta v_{j}$, where $\Delta v_{j}$ is a mesh increment, while in a second separate loop adds these temporarles together to form the functional $\mathrm{N}_{\ell}\left(\mathrm{V}_{\ell}^{\mathrm{b}}\right)\left(\mathrm{v}_{\mathrm{j}}\right)$. This serond loop does not vectorize since it is recursive.

(3) Determine the coefficients $\left\{B_{\ell}^{b}\left(v_{j}\right), \frac{\partial}{\partial v} B_{\ell}^{b}\left(v_{j}\right)\right.$, ecc $\} \underset{j=1}{J}($ Eqs. (24) - (29)). This is accomplished through a single vectorizable loop over " $\mathrm{f}$ ".

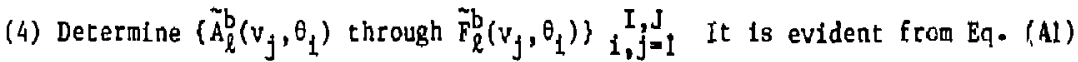
that the evaluation procedure is vectorizable. The theta ("I") loop is chosen on the outside, since it is normally much smaller than the velocity ("j") laop. The Legendre polynomlals and thetr derivatives are tme-1ndependent and are stored quantities. As the coeffictents $\tilde{A}_{\ell}^{b}-\tilde{F}_{l}^{b}$ are calculated, they are sinultaneously suramed over " $\ell$ " since it is the sum, $\sum_{\ell=0}^{4} c_{l}^{b}$, that 1 r required in Fg. (AI),

(5) Evaluate the contribution of the $b^{\text {th }}$ specles to the Fokker-Planck coefficlents $A_{a}\left(v_{j}, \theta_{1}, t\right)$ through $F_{a}\left(v_{j}, \theta_{1}, t\right)$ for all specieg "a" (see Eq. (A2)). This is accomplished w1thin the two outer loops over " $b$ " and " $\ell$ " and within a third loop over "a". The procedure easily vectorizeg. 